\title{
Phytoplankton community structure in one sector of Guanabara Bay (RJ, Brazil) during 2011 and 2012
}

\author{
Katia Regina Vieira de Rezende*, Melissa Medeiros Ferreira Hatherly, Cristiane Marques \\ Monteiro Pimenta, Janaina Eduardo, Simone de Castro Vianna, Norberto Mangiavacchi
}

GESAR, Unidade de Desenvolvimento Tecnológico, Universidade do Estado do Rio de Janeiro

(Rua Fonseca Teles, 121, São Cristóvão, Rio de Janeiro, Brazil)

*Corresponding author: katiarvr@gmail.com

\begin{abstract}
This study analyzed the temporal variability of phytoplankton assemblages in the surface waters of Guanabara Bay (RJ, Brazil), at six stations in front of Icaraí Inlet from April/2011 to April/2012. Our results highlight the great contribution of diatoms, dinoflagellates and cyanobacteria, represented by 111 taxa typical of estuarine and coastal areas. The coexistence of benthic and planktonic species suggests considerable hydrodinamism in these waters. All variables were homogeneous $(p>0.05)$ between the stations, but differed between sampling periods. On average, phytoplankton abundance $\left(10^{7}\right.$ cells. $\left.\mathrm{L}^{-1}\right)$ was higher than that of other estuaries and its temporal behavior was closely correlated $(p<0.01)$ with diatoms and cyanobacteria. The richness distribution pattern ( 7 to 27 taxa) was closely correlated $(p<0.01)$ with dinoflagellates and diatoms. Ninety per cent of all samples presented a low diversity index $(<2.0$ bits.cell $\left.{ }^{-1}\right)$, which indicated the unstable balance of the system, typical of environments subjected to eutrophication. The population structure analysis revealed that $10 \%$ of all taxa were resident, $12 \%$ visitors and $78 \%$ accidental, suggesting the influence of continental and oceanic water influxes. Between the "typical" taxa, the most common were the cyanobacteria of the order Oscillatoriales, the diatoms Ceratoneis closterium (=Cylindrotheca closterium) and Leptocylindrus minimus and the dinoflagellate Prorocentrum triestinum.
\end{abstract}

Descriptors: Tropical estuary, Temporal variation, Species Diversity, Microphytoplankton.

\section{RESUMO}

Este trabalho analisou a variabilidade sazonal da comunidade microfitoplanctônica em águas superficiais da Baía da Guanabara (RJ, Brasil) em 6 estações em frente à Enseada de Icaraí, de abril de 2011 a abril de 2012. Os resultados destacaram a alta representatividade de diatomáceas, dinoflagelados e cianobactérias, representados por 111 táxons típicos de ambientes estuarinos/costeiros. A coexistência de espécies bentônicas e planctônicas indicou o alto hidrodinamismo local. Houve homogeneidade $(p>$ $0,05)$ entre as estações de coleta para todas as variáveis, mas diferenças entre campanhas. A densidade média $\left(10^{7}\right.$ cel. $\left.\mathrm{L}^{-1}\right)$ foi superior à de outros sistemas estuarinos e seu comportamento temporal esteve altamente correlacionado $(p<0,01)$ com diatomáceas e cianobactérias. Por sua vez o padrão de distribuição da riqueza (7 a 27 táxons) apresentou alta correlação positiva $(p<0,01)$ com dinoflagelados e diatomáceas. Baixos índices de diversidade $\left(<2,0\right.$ bits.cel $\left.^{-1}\right)$ em $90 \%$ das amostras reafirmaram o equilíbrio instável do sistema, típico de ambientes sujeitos à eutrofização. A análise da estrutura das populações estabeleceu que $10 \%$ dos táxons são residentes, $12 \%$ visitantes e $78 \%$ acidentais, reafirmando a influência do aporte continental e/ou águas oceânicas. Entre os táxons "típicos", destacaram-se cianobactérias da Ordem Oscillatoriales, diatomáceas Ceratoneis closterium (=Cylindrotheca closterium) e Leptocylindrus minimus e o dinoflagelado Prorocentrum triestinum.

Descritores: Estuário tropical, Variação temporal, Diversidade específica, Microfitoplâncton. 


\section{INTRODUCTION}

The evaluation of the condition of an ecosystem requires the assessment of its primary productivity and trophic dynamics in view of the structure and ecological functions of its communities. Phytoplankton represents the basis of the main food webs in aquatic ecosystems, and its taxonomic composition and abundance respond to environmental disturbances (i.e. physical processes such as advective currents and turbulence, and chemical composition - nutrients), and to the interaction between species (i.e. competition for resources: light and nutrients) (MARGALEF, 1963; 1978). Consequently, the assessment of an aquatic ecosystem dynamics is relevant not only for the system's production, but also for the possibility of using organisms as an efficient proxy for determining natural and anthropogenic disturbances (LOBO; CALLEGARO; BENDER, 2002).

SIEBURTH, SMETACEK and LENZ (1978) proposed the classification of planktonic cells in three groups according to their size, named pico $(0.2-2 \mu \mathrm{m})$, nano $(2-20 \mu \mathrm{m})$ and microplankton $(20-200 \mu \mathrm{m})$. Because of their small size, these organisms present a short generation time (hours-days), and their rapid response to environmental conditions makes them good indicators of important environmental processes such as eutrophication (HARRIS， 1986; SOMMER, 1989; REYNOLDS; PADISÁK; SOMMER, 1993).

Coastal and estuarine areas present high productivity due to nutrient rich terrestrial inputs and anthropogenic effects on distinct temporal and spatial scales. The great hydrodynamism caused by these impacts increases the ability of these regions to sustain high primary production and metabolic rates of phytoplanktonic cells (CLOERN; FOSTER; KLECKNER, 2014), due to alterations in phytoplankton community structure that are reflected in the marine food web (JI et al., 2007; CLOERN; JASSBY, 2010; LLEBOT et al., 2011).

Guanabara Bay is one of the largest embayments of the Brazilian coast. It is shallow (5-50 m depth) but presents a north-south axis of $30 \mathrm{~km}$, a perimeter of $131 \mathrm{~km}$, an area of $384 \mathrm{~km}^{2}$, and $1.87 \times 10^{9} \mathrm{~m}^{3}$ of water volume (KJERFVE et al., 1997; KJERFVE, SEELIGER; LACERDA, 2001). The climate of this region is warm and wet all year around (average humidity of $78 \%$ and temperature of $23.7^{\circ} \mathrm{C}$ ), with a rainy season during spring-summer (September to March) and a drier period during autumn-winter (April to August), a seasonality that influences the hydrobiology of the bay. Hydrological characteristics respond to temporal (daily and seasonal) variations of tides and cold fronts (precipitation and winds), which influence the terrestrial freshwater inflow that impacts certain areas of the bay strongly: high precipitation in summer causes an increase of the terrestrial freshwater input, the opposite occurring in winter. The freshwater input is derived from river catchment basins, which receive domestic and industrial effluents (MAYR; TENENBAUM; VILLAC, 1989), and the input of coastal seawater increases during high tide (VALENTIN et al., 1999). Tides present a semi-diurnal regime (AMADOR, 1997) with average amplitude of $0.7 \mathrm{~m}$, ranging from $1.1 \mathrm{~m}$ during spring to $0.3 \mathrm{~m}$ in neap tide periods (JICA, 1994; VALENTIN et al., 1999; KJERFVE, SEELIGER; LACERDA, 2001). Guanabara Bay is surrounded by large urbanized areas such as the cities of Rio de Janeiro and Niterói (SCHWAMBORN et al., 2004), and by the second largest industrial park in the country, with around 6000 factories $1 \%$ of which account for $80 \%$ of the industrial pollution poured into the bay (CIDS, 2000). Because of these conditions, Guanabara Bay is considered a polluted eutrophic system (JICA, 1994), despite the processes of autodepuration that occur through interchanges with the ocean, which save the biota from irreversible damage (VALENTIN et al., 1999).

The sampling area is located in front of Icaraí Inlet $\left(22^{\circ} 55^{\prime} \mathrm{S}-43^{\circ} 08^{\prime} \mathrm{W}\right)$ in Niterói city, RJ (Figure 1). The waves that enter the inlet, coming from south and southwest, lead to great hydrodynamism in this area, especially during storm surges (SILVA; RESENDE; SANTOS, 1999; SANTOS; SILVA; SALVADOR, 2004).

Phytoplankton from Guanabara Bay has been studied since the early XX century, but most of the studies are scattered in academic thesis and dissertations. The first studies that include analyses of population dynamics as a function of environmental variables were published during the 80 's, and generated a broad characterization of the system's hydrobiology (MAYR; TENENBAUM; VILLAC, 1989). Recently, VILLAC and TENENBAUM (2010) have gathered information contained in 57 publications with data obtained between 1913 and 2004 in a state of art manuscript on the phytoplankton biodiversity of Guanabara Bay. The analysis of this information allowed them to conclude that, despite the fact that some of the studies published contain lists of microphytoplankton species, most of them adopt an ecological approach and highlight only the most abundant species. According to this historical study, the inventory of phytoplankton 


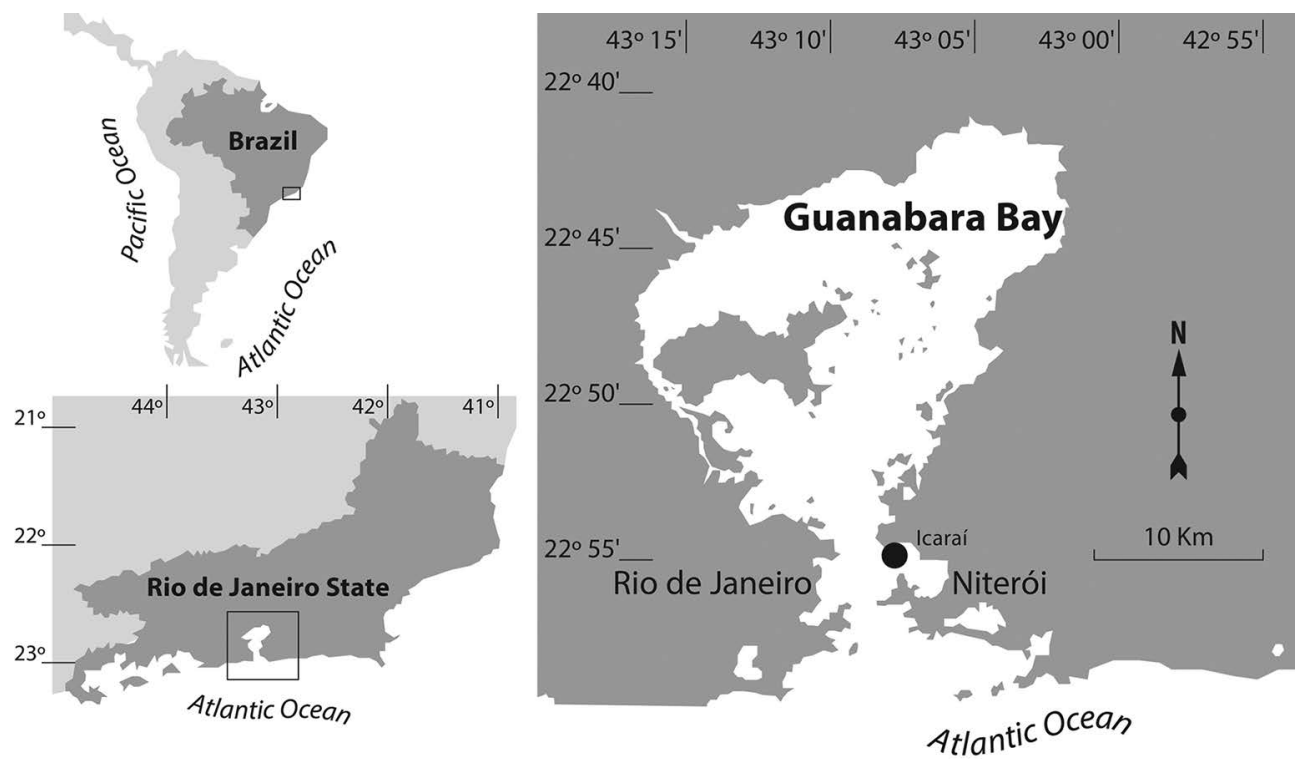

Figure 1. Map of Guanabara Bay showing location of the sampling area (Niterói, Rio de Janeiro).

species from Guanabara Bay totaled 308 taxa, with the dominance of diatoms (62\%) and dinoflagellates (32\%), and other groups such as cyanobacteria, euglenophyceans, chlorophyceans, prasinophyceans, silicoflagellates and ebriidae were also represented. Other studies revealed that, in Guanabara Bay, phytoplankton assemblages present spatial heterogeneity, and their abundance is comparable to that of intensely polluted estuaries.

Changes in phytoplankton communities due to the effects of natural events or pollutants can be determined by the investigation of the species' composition, cell numbers and diversity indices. Thus, the goal of this work is to describe the abundance and community structure of microphytoplankton in surface waters of one sector of Guanabara Bay, during the period between April 2011 and April 2012. These results broaden the information available on the temporal change of the phytoplankton of this system under the influence of the variation of coastal water quality and anthropogenic activities and may be valuable for future environmental monitoring and assessment programs.

\section{MATERIAL AND METHODS}

\section{SAMPLING AND ANALYSIS}

Surface water samples were taken using a Van Dorn bottle and then stored in 500 to $1000 \mathrm{ml}$ glass vials and fixed with a Lugol solution (THRONDSEN, 1978). Sampling was carried out fortnightly (36 samples) from April to June 2011, and monthly during the remaining period (60 samples) at six stations in front of Icaraí inlet (Figure 1). Microphytoplankton abundance and species composition were evaluated in accordance with HASLE (1978). Aliquotes of 2 to $10 \mathrm{ml}$ were analyzed by the UTERMOHL (1958) method, using inverted microscopes (Coleman NIB100 and Nikon TS100F) with phase contrast and 200x magnification. The phytoplankton counts were based on a minimum of 150 settled units (single cells, chainforming and filamentous organisms). In addition, the number of cells in each settled unit (SHAW, 1964; TENENBAUM et al., 2001; GUENTHER et al., 2012) was also registered and the results were expressed as cells per liter (cells. $\left.L^{-1}\right)$.

In order to avoid missing the richness per sample, organisms that could not be identified to the species level were classified into broader taxonomic groups (class, order and family) and identified by their morphotypes according to cells shape and dimension. We would point out that the identification of most taxa requires complex training and the utilization of more advanced microscopy techniques with a higher resolution (SOURNIA, 1978; TOMAS, 1997). The classification systems used for taxonomic denomination were those of ROUND, CRAWFORD and MANN (1990) for Diatoms, FENSOME et al. (1993) for dinoflagellates, KOMÁREK and ANAGNOSTIDIS $(1989 ; 2005)$ for cyanobacteria and THRONDSEN (1997) for Chlorophythes. 


\section{Data ANALYSIS}

The Kruskal-Wallis non-parametric test was used to test the temporal and spatial variability $(p<0.05)$ in phytoplankton abundance, richness and the ShannonWiener Diversity index. The Mann-Whitney nonparametric test was applied to compare co-temporal independent samples during the biweekly sampling period. To establish correlation between variables the Simple Linear Correlation (Pearson's r) test, that determines the extent to which values of the two variables are "proportional" to each other, was used. The analysis of microphytoplankton community structure was performed using three ecological indexes: a) the Constancy index: the taxon was considered "resident" when it was recorded in more than $50 \%$ of the samples, "visitor" when it was recorded in $25-50 \%$ of the samples and "accidental" when recorded in less than $25 \%$ of the samples (DAJOZ, 1983); b) the Shannon-Wiener Species Diversity index and c) Pielou's Evenness index (LEGENDRE; LEGENDRE, 1998). The analysis of Similarity Percentages (SIMPER) identified the taxa responsible for the similarity of samples in each sampling period (CLARKE; WARWICK, 1994). Some analyses (Kruskal-Wallis, Mann-Whitney and Simple Linear Correlation) were carried out using STATISTICA (Version 7), other routines (ShannonWiener Diversity, Pielou's Evenness and Simper analysis) were performed using PRIMER (Version 5).

\section{RESULTS}

\section{Specific COMPosition, Richness And Abundance}

A total of 110 taxa were identified, belonging to 4 Divisions (Figure 2; Table 1): Diatoms (55 taxa; 25 species), Dinoflagellates (51 taxa; 25 species), Cyanobacteria (2 taxa) and Chlorophythes (2 taxa).

Richness, Abundance, Diversity Index and Evenness results are presented as the mean values of each sampling period, as the non-parametric tests revealed no differences $(p<0.05)$ between sampling stations. Table 2 presents information on these variables in each sampling period.

The richness distribution pattern (9 to 23 taxa) was highly correlated $(p<0.01)$ with dinoflagellates $(\mathrm{r}=$ $0.77)$ and diatoms $(r=0.50)$ which, together, represented 56 to $100 \%$ of the total number of taxa, while other groups' contributions were low $(<3$ taxa per sample). Richness values lower than the total average (17 \pm 3 taxa) were registered in May, October and December 2011, and from January to April 2012. During the biweekly
(A)

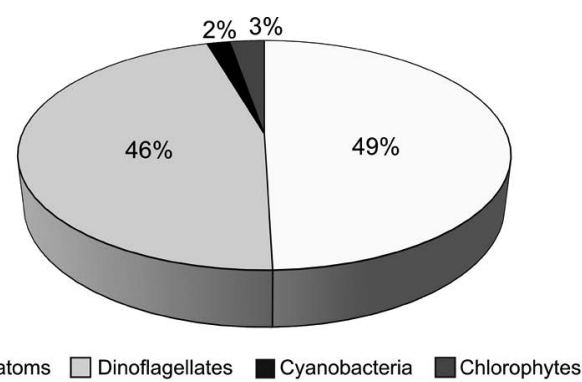

(B)

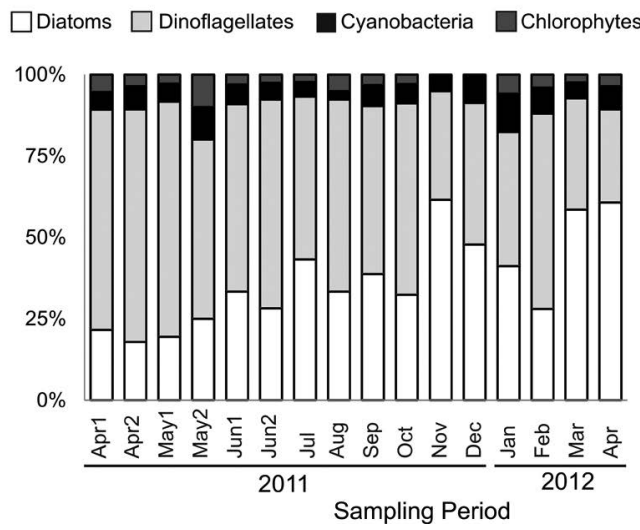

Figure 2. Percentage Contribution of Diatoms, Dinoflagellates, Cyanobacteria and Chlorophytes considering the entire study period (A) and separated by sampling cruise (B).

sampling period, only May presented a distinct $(p<$ 0.05 ) phytoplankton assemblage, with a low richness of dinoflagellates in the second sampling of the month (Figure 3).

Variations in abundance $\left(7.7 \times 10^{5}\right.$ to $7.0 \times 10^{7}$ cells. $\left.L^{-1}\right)$ were correlated $(p<0.01)$ with high cell density of diatoms $(\mathrm{R}=0.76)$ and cyanobacteria $(\mathrm{R}=0.67)$. Values lower than the total mean $\left(2.0 \times 10^{7} \pm 2.2 \times 10^{7}\right.$ cells. $\left.L^{-1}\right)$ were registered in most of the sampling periods (Figure 4). During the biweekly sampling period, differences $(p<0.05)$ were observed due to Diatom (April), Dinoflagellate (April and June), Cyanobacteria (May and June) and Euglenophycean (June) variability. Diatom abundances varied from $1.6 \mathrm{x}$ $10^{5}$ to $1.0 \times 10^{8}$ cells. $L^{-1}\left(1.3 \times 10^{7} \pm 1.9 \times 10^{7}\right.$ cells. $\left.L^{-1}\right)$, and this group was dominant in all sampling periods (mean contribution of 66\%), except in April2 and October 2011 and February 2012. Cyanobacteria were represented by the Orders Oscillatoriales and Nostocales, showing abundances between $5.7 \times 10^{3}$ and $4.2 \times 10^{7}$ cells.L $L^{-1}\left(6.3 \times 10^{6} \pm 1.2\right.$ $\mathrm{x} 10^{7}$ cell. $\left.\mathrm{L}^{-1}\right)$. Amongst the cyanobacteria, the Order Oscillatoriales was the most numerous throughout the sampling periods, with an average contribution of $79 \%$. The mean abundances of Dinoflagellates and Chlorophythes were of the order of $10^{5}$ cells. $\mathrm{L}^{-1}$ and $10^{4}$ cell. $\mathrm{L}^{-1}$, respectively, with an average contribution lower than $7 \%$. 
Table 1. List of taxa found in Guanabara Bay from April 2011 to April 2012 indicating percentage of occurrence (\%) in all samples $(\mathrm{n}=96)$, classification by Constancy Index $(\mathrm{R}=$ resident; $\mathrm{V}=$ visitor and $\mathrm{A}=$ accidental $)$ and occurrence by month $(n=13)$. The following classification systems were adopted: Round, Crawford and Mann (1990) for Diatoms (Bacillariophyta); Fensome et al. (1993) for dinoflagellates (Dinoflagellata); Komárek and Anagnostidis (1989; 2005) for cyanobacteria (Cyanophyta) and Throndsen (1997) for Chlorophythes (Chlorophyta). The morphotypes are not included in this table.

\begin{tabular}{|c|c|c|c|c|c|c|c|c|c|c|c|c|c|c|c|}
\hline \multirow{3}{*}{$\begin{array}{l}\text { TAXONOMY } \\
\text { CATEGORY }\end{array}$} & \multirow{3}{*}{$\begin{array}{c}\text { Total Occurrence } \\
(\%) n=96\end{array}$} & \multirow{3}{*}{$\begin{array}{c}\text { Constancy } \\
\text { Index }\end{array}$} & \multicolumn{13}{|c|}{ Occurrence by month $(n=13)$} \\
\hline & & & \multicolumn{9}{|c|}{2011} & \multicolumn{4}{|c|}{2012} \\
\hline & & & Apr & May & Jun & Jul & Aug & Sep & Oct & Nov & Dec & Jan & Feb & Mar & Apr \\
\hline \multicolumn{16}{|l|}{ Division Bacillariophyta } \\
\hline \multicolumn{16}{|l|}{ Class Coscinodiscophyceae } \\
\hline \multicolumn{16}{|l|}{ Order Thalassiosirales } \\
\hline \multicolumn{16}{|l|}{ Family Thalassiosiraceae } \\
\hline Thalassiosira sp. & 18 & A & $*$ & & & $*$ & $*$ & & * & $*$ & $*$ & & & $*$ & $*$ \\
\hline \multicolumn{16}{|l|}{ Family Skeletonemataceae } \\
\hline $\begin{array}{l}\text { Skeletonema cf. costatum } \\
\text { (Greville) Cleve }\end{array}$ & 25 & A & $*$ & & $*$ & $*$ & & & $*$ & $*$ & & & & $*$ & $*$ \\
\hline Skeletonema sp. & 6 & A & & & & & & $*$ & $*$ & & & & & & \\
\hline \multicolumn{16}{|l|}{ Order Paraliales } \\
\hline \multicolumn{16}{|l|}{ Family Paraliaceae } \\
\hline Paralia sulcata (Ehrenberg) Cleve & 1 & A & & & & & & & & $*$ & & & & & \\
\hline \multicolumn{16}{|l|}{ Order Coscinodiscales } \\
\hline \multicolumn{16}{|l|}{ Family Coscinodiscaceae } \\
\hline Coscinodiscus sp. & 1 & A & & & & & & & & & & & & & $*$ \\
\hline \multicolumn{16}{|l|}{ Order Triceratiales } \\
\hline \multicolumn{16}{|l|}{ Family Triceratiaceae } \\
\hline $\begin{array}{l}\text { Odontella aurita (Lyngbye) C. } \\
\text { Agardh }\end{array}$ & 1 & A & & & & & & & & $*$ & & & & & \\
\hline \multicolumn{16}{|l|}{ Order Hemiaulales } \\
\hline \multicolumn{16}{|l|}{ Family Hemiaulaceae } \\
\hline $\begin{array}{l}\text { Cerataulina pelagica } \\
\text { (Cleve) Hendey }\end{array}$ & 3 & A & & & & & & & & $*$ & & & & & \\
\hline $\begin{array}{l}\text { Eucampia cornuta } \\
\text { (Cleve) Grunow }\end{array}$ & 1 & A & & & & & & & & $*$ & & & & & \\
\hline Eucampia sp. & 1 & A & & & & & & & & $*$ & & & & & \\
\hline Hemiaulus membranaceus Cleve & 1 & A & & & & & & & & $*$ & & & & & \\
\hline \multicolumn{16}{|l|}{ Order Rhizosoleniales } \\
\hline \multicolumn{16}{|l|}{ Family Rhizosoleniaceae } \\
\hline $\begin{array}{l}\text { Dactyliosolen fragilissimus } \\
\text { (Bergon) Hasle }\end{array}$ & 1 & A & & & & & & & & & & & & & $*$ \\
\hline $\begin{array}{l}\text { Dactyliosolen phuketensis (B. G. } \\
\text { Sundström) G. R. Hasle }\end{array}$ & 2 & A & & & & & & & & & * & & & & \\
\hline $\begin{array}{l}\text { Guinardia flaccida } \\
\text { (Castracane) H. Peragallo }\end{array}$ & 1 & A & & $*$ & & & & & & & & & & & \\
\hline $\begin{array}{l}\text { Guinardia striata } \\
\text { (Stolterfoth) Hasle }\end{array}$ & 2 & A & & & & * & & & & & & & & $*$ & \\
\hline Guinardia sp. & 15 & A & & & $*$ & $*$ & & $*$ & & & & & & & \\
\hline $\begin{array}{l}\text { Proboscia alata } \\
\text { (Brightwell) Sundström }\end{array}$ & 2 & A & & & $*$ & & & & & & & & & & $*$ \\
\hline Rhizosolenia setigera Brightwell & 42 & $\mathrm{~V}$ & $*$ & & & $*$ & $*$ & $*$ & $*$ & $*$ & $*$ & & & $*$ & $*$ \\
\hline $\begin{array}{l}\text { Rhizosolenia setigera f. pungens } \\
\text { (Cleve-Euler) Brunel }\end{array}$ & 2 & A & & & & & & & & & $*$ & & & & \\
\hline \multicolumn{16}{|l|}{ Order Chaetocerotales } \\
\hline Family Chaetocerotaceae & & & & & & & & & & & & & & & \\
\hline
\end{tabular}


Continued Table 1.

\begin{tabular}{|c|c|c|c|c|c|c|c|c|c|c|c|c|c|c|c|}
\hline Chaetoceros compressus Lauder & 3 & A & & & & & & & & $*$ & $*$ & & & & \\
\hline Chaetoceros curvisetum Cleve & 2 & A & & & & & & & & $*$ & & & & & \\
\hline Chaetoceros danicus Cleve & 6 & A & & & & & & $*$ & & $*$ & & & & & * \\
\hline Chaetoceros radians $\mathrm{F}$. Schütt & 2 & A & & & & & & $*$ & $*$ & & & & & & \\
\hline Chaetoceros socialis $\mathrm{H}$. S. Lauder & 1 & A & & & & & & & & & & & & & * \\
\hline Chaetoceros cf. socialis H. S. Lauder & 4 & A & & & & & & & & $*$ & & & & & \\
\hline Chaetoceros spp. & 15 & A & & * & $*$ & & & $*$ & & $*$ & $*$ & & & $*$ & \\
\hline \multicolumn{16}{|l|}{ Order Leptocylindrales } \\
\hline \multicolumn{16}{|l|}{ Family Leptocylindraceae } \\
\hline Leptocylindrus danicus Cleve & 31 & $\mathrm{~V}$ & $*$ & & * & $*$ & * & & * & $*$ & $*$ & $*$ & $*$ & $*$ & * \\
\hline Leptocylindrus minimus Gran & 76 & $\mathrm{R}$ & $*$ & * & $*$ & $*$ & $*$ & $*$ & $*$ & $*$ & $*$ & $*$ & $*$ & $*$ & * \\
\hline \multicolumn{16}{|l|}{ Class Flagilariophyceae } \\
\hline \multicolumn{16}{|l|}{ Order Fragilariales } \\
\hline \multicolumn{16}{|l|}{ Family Fragilariaceae } \\
\hline $\begin{array}{l}\text { Asterionellopsis glacialis } \\
\text { (Castracane) Round }\end{array}$ & 5 & A & & & & & * & & * & $*$ & & & & $*$ & \\
\hline \multicolumn{16}{|l|}{ Order Licmophorales } \\
\hline \multicolumn{16}{|l|}{ Familia Licmophoraceae } \\
\hline Licmophora sp. & 1 & A & & & & $*$ & & & & & & & & & \\
\hline \multicolumn{16}{|l|}{ Order Thalassionematales } \\
\hline \multicolumn{16}{|l|}{ Familia Thalassionemataceae } \\
\hline $\begin{array}{l}\text { Thalassionema nitzschioides } \\
\text { (Grunow) Mereschkowsky }\end{array}$ & 5 & A & & & & $*$ & & & & & & & & $*$ & * \\
\hline \multicolumn{16}{|l|}{ Class Bacillariophyceae } \\
\hline \multicolumn{16}{|l|}{ Family Phaeodactylaceae } \\
\hline Phaeodactylum tricornutum Bohlin & 11 & A & & & & & & & & $*$ & & & $*$ & $*$ & $*$ \\
\hline \multicolumn{16}{|l|}{ Family Diploneidaceae } \\
\hline Diploneis sp. & 6 & A & & & & $*$ & $*$ & $*$ & * & & & & & & \\
\hline \multicolumn{16}{|l|}{ Family Naviculaceae } \\
\hline Complex Tropidoneis & 3 & A & & & & & & & & $*$ & & & & & \\
\hline \multicolumn{16}{|l|}{ Family Pleurosigmataceae } \\
\hline Complex Pleurosigma/Gyrosigma & 4 & A & & * & & & & & & & & & & $*$ & * \\
\hline \multicolumn{16}{|l|}{ Order Thalassiophysales } \\
\hline \multicolumn{16}{|l|}{ Family Catenulaceae } \\
\hline Amphora sp. & 1 & A & & & & & $*$ & & & & & & & & \\
\hline \multicolumn{16}{|l|}{ Order Bacillariales } \\
\hline \multicolumn{16}{|l|}{ Family Bacillariaceae } \\
\hline $\begin{array}{l}\text { Complex C. closterium/Nitzschia } \\
\text { longissima }\end{array}$ & 7 & A & & & & $*$ & $*$ & & & & & & & & \\
\hline $\begin{array}{l}\text { Ceratoneis closterium Ehrenberg } \\
(=\text { Cylindrotheca } \text { closterium })\end{array}$ & 97 & $\mathrm{R}$ & $*$ & $*$ & $*$ & $*$ & $*$ & $*$ & $*$ & $*$ & $*$ & $*$ & $*$ & $*$ & * \\
\hline $\begin{array}{l}\text { Pseudo-nitzschia "complex } \\
\text { delicatissima" }\end{array}$ & 14 & A & $*$ & & $*$ & & $*$ & $*$ & & & & $*$ & & $*$ & \\
\hline Pseudo-nitzschia "complex seriata" & 4 & A & & & & & & & & $*$ & & $*$ & & $*$ & \\
\hline Division DINOFLAGELLATA & & & & & & & & & & & & & & & \\
\hline Class Dinophyceae & & & & & & & & & & & & & & & \\
\hline Order Gymnodiniales & & & & & & & & & & & & & & & \\
\hline
\end{tabular}


Continued Table 1.

\begin{tabular}{|c|c|c|c|c|c|c|c|c|c|c|c|c|c|c|c|c|}
\hline Amphidinium spp. & 27 & $\mathrm{~V}$ & $*$ & * & * & * & * & * & $*$ & * & & * & & & & \\
\hline Gymnodinium spp. & 6 & A & & $*$ & & & & & & & & & & & & \\
\hline $\begin{array}{l}\text { Gyrodinium } \text { cf. spirale (Bergh) } \\
\text { Kofoid \& Swezy }\end{array}$ & 2 & $\mathrm{~A}$ & & & $*$ & & & & & & & & & & & \\
\hline Gyrodinium spp. & 2 & A & & & $*$ & & & & & & & & & & & \\
\hline \multicolumn{17}{|l|}{ Order Gonyaulacales } \\
\hline \multicolumn{17}{|l|}{ Family Goniodomaceae } \\
\hline Alexandrium spp. & 1 & A & $*$ & & & & & & & & & & & & & \\
\hline \multicolumn{17}{|l|}{ Order Peridiniales } \\
\hline \multicolumn{17}{|l|}{ Family Peridiniaceae } \\
\hline $\begin{array}{l}\text { Scrippsiella } \text { cf. spinifera } \text { G. Honsell } \\
\text { \& M. Cabrini }\end{array}$ & 2 & A & $*$ & & & & & & & & & & & & & \\
\hline $\begin{array}{l}\text { Scrippsiella } \text { cf. trochoidea (Stein) } \\
\text { Balech ex Loeblich III }\end{array}$ & 31 & $\mathrm{~V}$ & $*$ & * & $*$ & $*$ & * & & & & & & & & & \\
\hline Scrippsiella sp. & 28 & $\mathrm{~V}$ & $*$ & & $*$ & $*$ & * & $*$ & $*$ & $*$ & $*$ & $*$ & & & $*$ & \\
\hline \multicolumn{17}{|l|}{ Family Congruentidiaceae } \\
\hline $\begin{array}{l}\text { Protoperidinium cf. bipes } \\
\text { (Paulsen) Balech }\end{array}$ & 5 & A & & & $*$ & * & * & * & $*$ & & & & & & & \\
\hline $\begin{array}{l}\text { Protoperidinium cf. steinii } \\
\text { (Jorgensen) Balech }\end{array}$ & 1 & A & & & & * & * & & & & & & & & & \\
\hline Protoperidinium spp. & 43 & $\mathrm{~V}$ & $*$ & $*$ & $*$ & * & * & $*$ & $*$ & $*$ & & & & & $*$ & * \\
\hline \multicolumn{17}{|l|}{ Order uncertain } \\
\hline \multicolumn{17}{|l|}{ Family Oxytoxaceae } \\
\hline Oxytoxum crassum Schiller & 5 & $\mathrm{~A}$ & $*$ & & $*$ & & & & & $*$ & & & & & & \\
\hline Oxytoxum cf. gladiolus Stein & 2 & $\mathrm{~A}$ & & & & & & * & & $*$ & & & & & & \\
\hline Oxytoxum gracile Schiller & 7 & A & & * & & * & * & * & $*$ & & & $*$ & & & & \\
\hline Oxytoxum laticeps Schiller & 3 & A & & & & * & & & & $*$ & & & & * & & \\
\hline Oxytoxum scolopax Stein & 2 & A & $*$ & $*$ & & & & & & & & & & & & \\
\hline Oxytoxum cf. turbo Kofoid & 1 & A & & & & & & $*$ & & & & & & & & \\
\hline Oxytoxum sp. & 1 & A & & $*$ & & & & & & & & & & & & \\
\hline \multicolumn{17}{|l|}{ Order Dinophysiales } \\
\hline \multicolumn{17}{|l|}{ Family Dinophysiaceae } \\
\hline $\begin{array}{l}\text { Dinophysis acuminata Claparède } \\
\text { \& Lachmann }\end{array}$ & 9 & A & $*$ & $*$ & $*$ & * & & $*$ & $*$ & & * & & & & & \\
\hline Dinophysis fortii Pavillard & 3 & A & $*$ & & & & & & & & & & & & & \\
\hline Dinophysis sp. & 2 & A & $*$ & & & & & & & & * & & & & & \\
\hline \multicolumn{17}{|l|}{ Family Oxyphysaceae } \\
\hline Oxyphysis oxytoxoides Kofoid & 38 & $\mathrm{~V}$ & $*$ & $*$ & $*$ & * & & $*$ & $*$ & $*$ & & $*$ & & * & & \\
\hline \multicolumn{17}{|l|}{ Order Prorocentrales } \\
\hline \multicolumn{17}{|l|}{ Family Prorocentraceae } \\
\hline $\begin{array}{l}\text { Prorocentrum balticum (Lohmann) } \\
\text { Loeblich }\end{array}$ & 4 & A & $*$ & & $*$ & & & & & & & & & & $*$ & \\
\hline $\begin{array}{l}\text { Prorocentrum compressum } \\
\text { (J. W. Bailey) Abé ex Dodge }\end{array}$ & 2 & A & & $*$ & $*$ & & & & & & & & & & & \\
\hline Prorocentrum dentatum Stein & 1 & A & & & & & & & & & $*$ & & & & & \\
\hline Prorocentrum gracile Schütt & 5 & A & $*$ & & & & & & & & & & & & & \\
\hline Prorocentrum micans Ehrenberg & 47 & $\mathrm{~V}$ & $*$ & $*$ & $*$ & * & & $*$ & $*$ & $*$ & $*$ & & $*$ & $*$ & $*$ & * \\
\hline $\begin{array}{l}\text { Prorocentrum minimum (Pavillard) } \\
\text { J. Schiller }\end{array}$ & 40 & $\mathrm{~V}$ & $*$ & $*$ & $*$ & * & & $*$ & $*$ & $*$ & $*$ & & $*$ & $*$ & $*$ & \\
\hline Prorocentrum scutellum Schröder & 2 & A & $*$ & & & & & & & & & & & & & \\
\hline Prorocentrum triestinum J. Schiller & 79 & $\mathrm{R}$ & $*$ & $*$ & $*$ & * & & $*$ & $*$ & $*$ & $*$ & $*$ & $*$ & $*$ & $*$ & $*$ \\
\hline Prorocentrum sp. & 7 & A & & & & & & $*$ & & $*$ & & $*$ & & & $*$ & \\
\hline
\end{tabular}


Continued Table 1.

\begin{tabular}{|c|c|c|c|c|c|c|c|c|c|c|c|c|c|c|c|}
\hline \multicolumn{16}{|l|}{ Class Noctiluciphyceae } \\
\hline \multicolumn{16}{|l|}{ Order Noctilucales } \\
\hline \multicolumn{16}{|l|}{ Family Noctilucaceae } \\
\hline $\begin{array}{l}\text { Pronoctiluca pelagica } \\
\text { Fabre-Domérgue }\end{array}$ & 3 & A & * & & & & & & & & & & * & & \\
\hline $\begin{array}{l}\text { Pronoctiluca spinifera } \\
\text { (Lohmann) Schiller }\end{array}$ & 2 & A & & & & & * & & * & & & & & & \\
\hline Division Chlorophyta & 5 & A & & * & & & * & & & & & & & & \\
\hline Class Euglenophyceae & 73 & $\mathrm{R}$ & * & $*$ & * & * & * & $*$ & * & & & $*$ & * & * & * \\
\hline Eutreptiella sp. & 1 & A & $*$ & & & & & & & & & & & & \\
\hline \multicolumn{16}{|l|}{ Division Cyanophyta } \\
\hline \multicolumn{16}{|l|}{ Class Cyanophyceae } \\
\hline Order Nostocales & 67 & $\mathrm{R}$ & $*$ & $*$ & * & $*$ & & $*$ & $*$ & $*$ & $*$ & $*$ & * & * & * \\
\hline Order Oscillatoriales & 91 & $\mathrm{R}$ & $*$ & * & * & * & * & $*$ & * & * & * & * & * & * & * \\
\hline
\end{tabular}

Table 2. Microphytoplankton (Total and by groups) Richness, Abundance and Ecological Indexes (Species Diversity and Evenness) from April 2011 to April 2012.

\begin{tabular}{|c|c|c|c|c|c|c|c|c|c|c|c|c|}
\hline \multirow[t]{2}{*}{ Date } & \multicolumn{5}{|c|}{ Richness } & \multicolumn{5}{|c|}{ Abundance } & \multicolumn{2}{|c|}{ Index } \\
\hline & Total & Diatoms & Dinoflagellates & Cyanobacteria & Chlorophythes & Total & Diatoms & Dinoflagellates & Cyanobacteria & Chlorophythes & $\begin{array}{l}\text { Species } \\
\text { Diversity }\end{array}$ & Evenness \\
\hline Apr1 & 18 & 4 & 12 & 1 & 1 & 35580718 & 10284643 & 24712437 & 410283 & 173355 & 0.44 & 0.15 \\
\hline Apr2 & 17 & 2 & 12 & 1 & 1 & 69754673 & 45297123 & 19789149 & 4639174 & 29226 & 0.44 & 0.15 \\
\hline May1 & 18 & 3 & 13 & 2 & 1 & 4107270 & 2244201 & 1392402 & 430008 & 40659 & 0.33 & 0.14 \\
\hline May2 & 12 & 2 & 6 & 2 & 2 & 6631668 & 4894936 & 360093 & 905809 & 470830 & 0.10 & 0.07 \\
\hline Jun1 & 19 & 6 & 10 & 2 & 1 & 18664938 & 17702565 & 189872 & 486232 & 286269 & 1.14 & 0.42 \\
\hline Jun2 & 20 & 5 & 13 & 1 & 1 & 10407854 & 9241535 & 93210 & 1051068 & 53111 & 0.94 & 0.34 \\
\hline Jul & 23 & 10 & 11 & 2 & 1 & 56865758 & 56645156 & 118060 & 66902 & 35640 & 0.99 & 0.33 \\
\hline Aug & 19 & 5 & 12 & 1 & 1 & 28571795 & 27728657 & 125740 & 439361 & 278036 & 0.11 & 0.04 \\
\hline Sep & 18 & 5 & 9 & 2 & 1 & 13277285 & 12723868 & 286800 & 203216 & 63401 & 0.10 & 0.04 \\
\hline Oct & 16 & 5 & 8 & 2 & 1 & 10212120 & 2486926 & 7372138 & 246037 & 107019 & 1.08 & 0.37 \\
\hline Nov & 18 & 10 & 6 & 1 & - & 768861 & 718381 & 5652 & 46713 & - & 1.57 & 0.48 \\
\hline Dec & 13 & 7 & 4 & 2 & - & 12459305 & 10876155 & 1569261 & 13889 & - & 0.16 & 0.07 \\
\hline Jan & 9 & 3 & 4 & 2 & 1 & 2728105 & 1885932 & 531635 & 306591 & 3946 & 1.03 & 0.51 \\
\hline $\mathrm{Feb}$ & 16 & 5 & 9 & 2 & 1 & 53614363 & 10990133 & 42197291 & 405632 & 21308 & 0.81 & 0.33 \\
\hline Mar & 17 & 9 & 6 & 2 & 1 & 2168300 & 851195 & 1197935 & 109175 & 9996 & 1.07 & 0.40 \\
\hline Apr & 15 & 7 & 5 & 2 & 1 & 1454119 & 345550 & 1008292 & 84125 & 16152 & 1.49 & 0.60 \\
\hline
\end{tabular}

\section{Community Structure}

According to the Constancy analysis in the study area (Table 1), $78 \%$ of the taxa were categorized as ACCIDENTAL (49 diatoms; 36 dinoflagellates; 2 chlorophythes), $10 \%$ as RESIDENT (3 diatoms; 5 dinoflagellates, 2 cyanobacteria, 1 chlorophythe), and $12 \%$ as VISITORS (3 diatoms; 10 dinoflagellates).

The Shannon-Wiener diversity index varied between 0.10 and 1.57 bits.cell $^{-1}$ (Table 2), with most values (56\%) higher than the mean $\left(0.74 \pm 0.50\right.$ bits.cell $^{-1}$; Figure 5$)$. The lowest values were registered in April, May, August, September and December 2011, related to high abundances of certain taxa of Diatoms and Dinoflagellates. Pielou's evenness varied from 0.04 to $0.60(0.28 \pm 0.18)$, following the same pattern as the diversity index (Figure 5).

A total of 42 taxa (19 diatoms, 19 dinoflagellates, 2 cyanobacteria and 2 chlorophythes) was defined by SIMPER analysis as the most representative ("typical") in the study area (Table 3), for their contribution of up to $90 \%$ of the similarity between the samples of each sampling period. The taxonomic classes with the greatest contributions to the similarity between samples were the dinoflagellates (13-60\%) and diatoms (13-55\%) (Figure 6). Individual contribution to sample similarity by a singular taxon varied between 2 and 19\% in each sampling period. We highlight unidentified cyanobacteria 


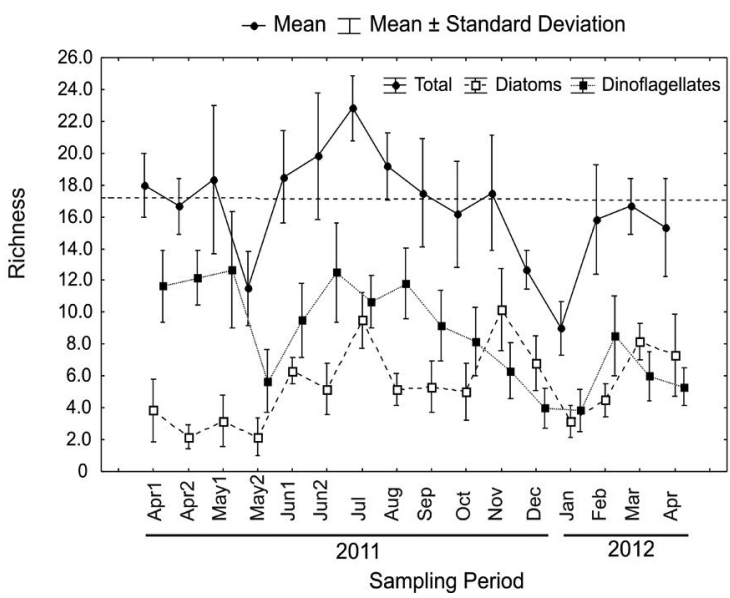

Figure 3. Total Microphytoplankton, Diatoms and Dinoflagellates Richness from April 2011 to April 2012. Dotted line indicates general mean of Total Richness.

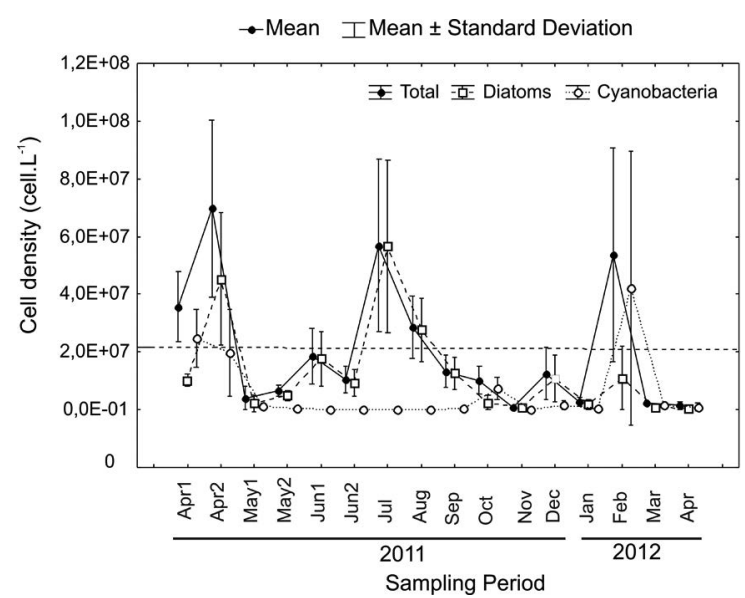

Figure 4. Total Microphytoplankton, Diatoms and Dinoflagellates Abundance (cell.L-1) from April 2011 to April 2012. Dotted line indicates general mean of Total Density.

of the Order Oscillatoriales and Order Nostocales, diatoms Ceratoneis closterium ( $=$ Cylindrotheca closterium) and Leptocylindrus minimum and dinoflagellate Prorocentrum triestinum for their broad occurrence $(>80 \%)$ with high mean abundance $\left(10^{4}-10^{7}\right.$ cells. $\left.\mathrm{L}^{-1}\right)$ in many periods. Table 3 shows the high abundance of certain morphotypes with several shapes and dimensions between 20 and $150 \mu \mathrm{m}$ (1 centric diatom, 4 pennate diatoms and 8 dinoflagellates) and brings out the need for taxonomic studies so that species that make a major contribution to community structure may be correctly identified.

When compared with the Constancy index, SIMPER analysis was more effective in determining which taxa made a greater contribution to sample similarity in each

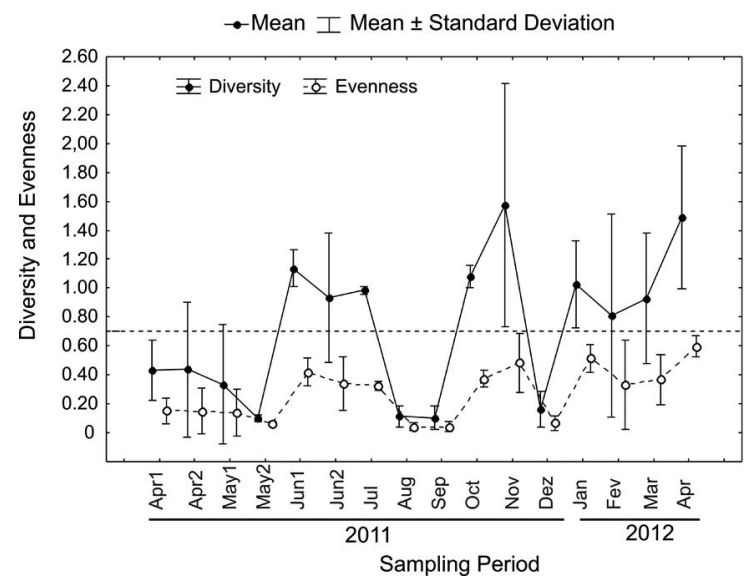

Figure 5. Shannon-Wiener Species Diversity index (bits.cell ${ }^{-1}$ ) and Pielou's Evenness index from April 2011 to April 2012. Dotted line indicates general mean of Diversity index.

period. The Constancy index just takes into account the occurrence of each taxon, while SIMPER considers abundance as well as occurrence. This could be observed for the diatom Skeletonema costatum classified as ACCIDENTAL by the Constancy index with occurrence in only $25 \%$ of the samples. However, this taxon was highlighted by SIMPER for its high mean densities $\left(2.8 \times 10^{6}-2.2 \times 10^{7}\right.$ cells. $\left.L^{-1}\right)$ that favored a contribution of up to $12 \%$ for the similarity of the samples for the periods of June1, June2 and July.

\section{DISCUSSION}

The microphytoplankton community of Guanabara Bay was characterized by typical estuarine and coastal species, influenced by a large number of multifactorial abiotic and biotic processes (LLEBOT et al., 2011; CLOERN; FOSTER; KLECKNER, 2014). Among all the factors that may affect the taxonomic composition and temporal variation of phytoplankton in Guanabara Bay are found: tidal cycle, seasonality of water masses of adjacent continental shelf, cold fronts and continental drainage (rainfall, inflow of domestic sewage, etc.)

The elevated number of taxa classified as ACCIDENTAL confirmed the high local hydrodynamism as being a consequence of the environmental factors mentioned above. The processes which caused such turbulence were probably responsible for the presence of benthic species (diatoms Paralia sulcata, Licmophora sp., Diploneis sp., Amphora sp.) along with planktonic ones (diatoms Leptocylindrus danicus, L. minimus, 


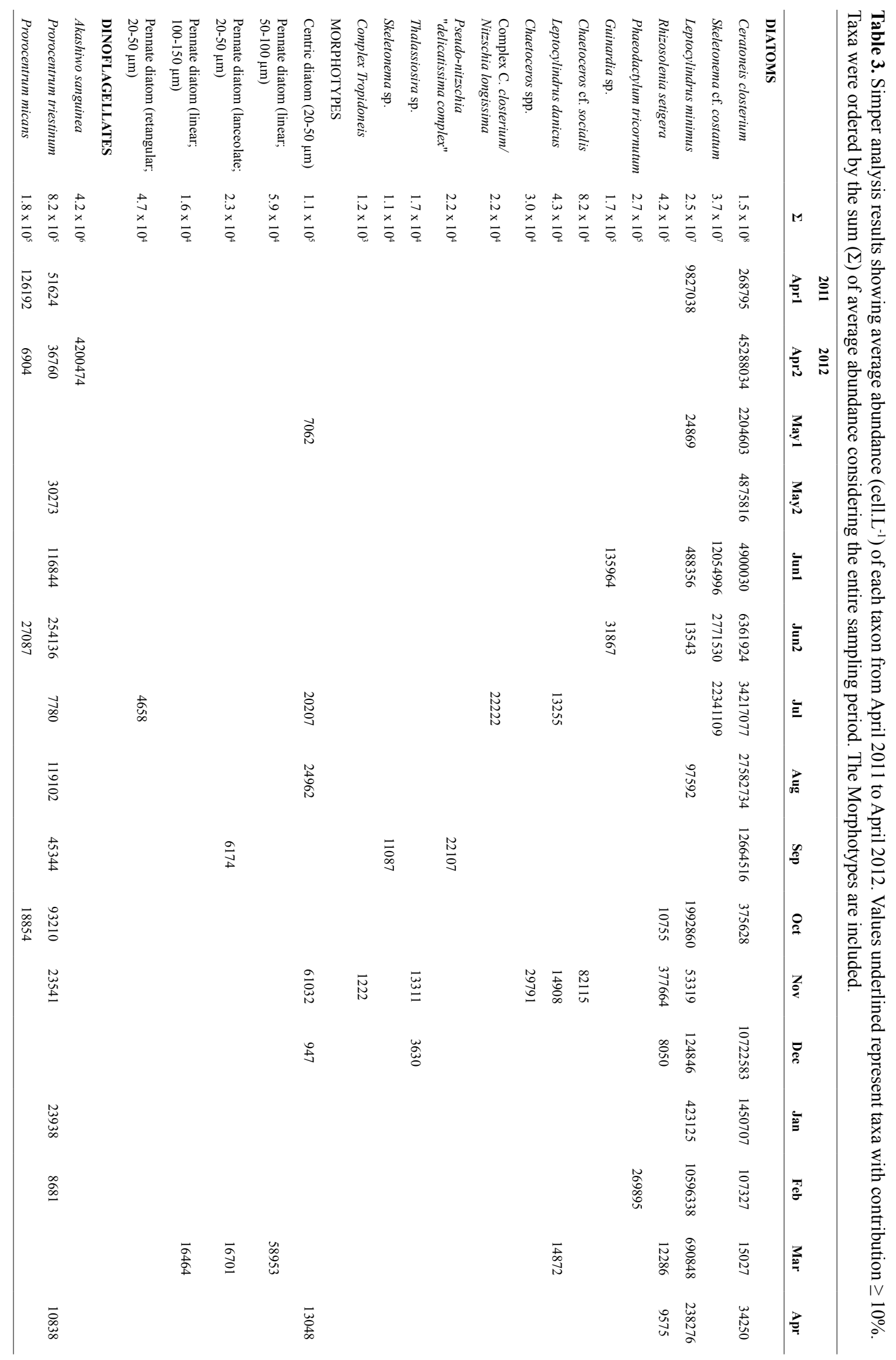




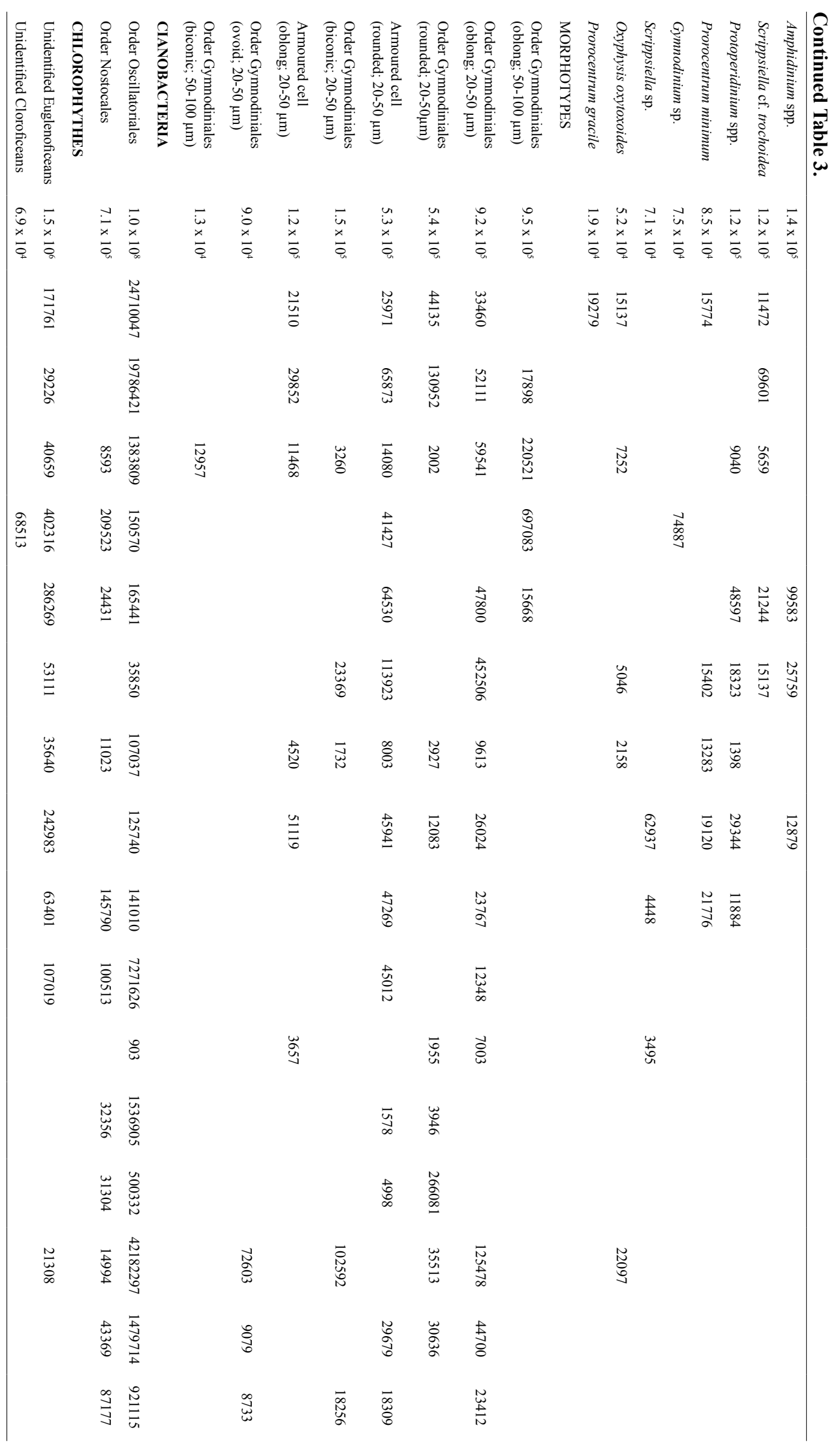




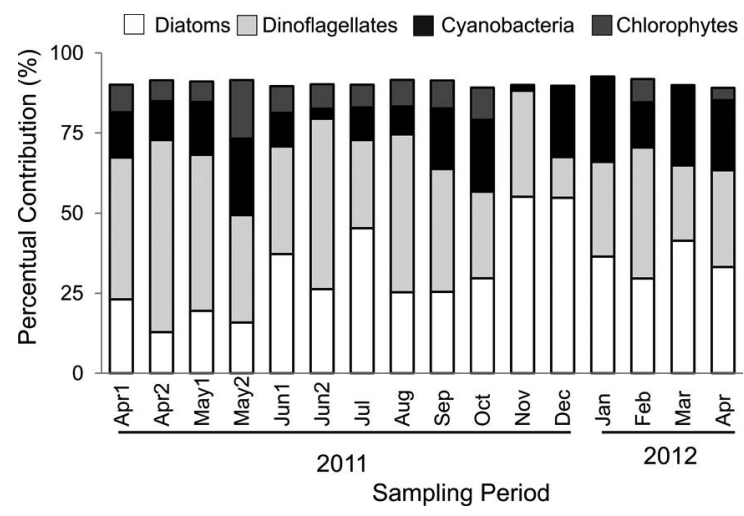

Figure 6. Percentual Contribution of phytoplankton groups determined by similarity percentage analysis (SIMPER).

Thalassionema nitzschioides, Coscinodiscus spp., Pseudo-nitzschia spp., Skeletonema cf. costatum; Dinoflagellates Alexandrium sp.; Protoperidinium spp.) (RICARD, 1987; HASLE; SYVERTSEN, 1997). It is important to state that benthic microalgae are important primary producers in shallow aquatic ecosystems and that their production exceeds that of planktonic microalgae in certain periods (BERGESCH; ODEBRECHT; ABREU, 1995; BRANDINI; FERNANDES, 1996). The relevance of a taxon in the study area was determined by its high contribution to sample similarity in each season. Thus SIMPER analysis confirmed the representativity of "RESIDENT" taxa as well as the occasional contribution of others during the study period.

The organisms identified in the present study had already been observed in Guanabara Bay due to their wide distribution in the system (VILLAC; TENENBAUM, 2010). The low frequency and abundance of Skeletonema costatum called the authors' attention since this diatom has been consistently reported as opportunist in eutrophic environments. This pattern change may be associated with the location of the sampling stations close to the bay's entrance, a less polluted site due to the contribution of more saline, cleaner and clearer coastal water (SANTOS et al., 2007). Similar results were found by GUENTHER et al. (2012) in a short temporal scale investigation also in the entrance of Guanabara Bay during summer 2004, in which S. costatum was not considered an abundant taxon. Likewise, SANTOS et al. (2007) registered higher densities of this species in the inner portion when compared with the entrance of the bay. These outcomes suggest that the hydrodynamic conditions found in different areas of Guanabara Bay may exercise great influence on the representation of $S$. costatum. Another important aspect to be considered is that this diatom was the subject of a taxonomic review revealing that the genus biodiversity at any given place is most likely underestimated and may include more than one species (SARNO et al., 2007; KOISTRA et al., 2008). For instance, the morphology of Skeletonema species was examined in coastal waters of southern Brazil and the authors came to the conclusion that this genus is highly diverse in that geographical area, with the occurrence of four confirmed species: S. costatum, S. pseudocostatum, S. potamos and S. tropicum (BERGESCH; GARCIA; ODEBRECHT, 2009).

The recurrent observation of potentially harmful species in the bay requires some attention, specially concerning diatoms of the genus Pseudo-nitzschia due to its ability to produce a powerful neurotoxin known as domoic acid (VILLAC; TENENBAUM, 2001; VILLAC; DOUCETTE; KACZMARSKA, 2010). Some studies have shown that Pseudo-nitzschia abundance is related to a major entry of nutrients into the water column (PARSON; DORTCH, 2002). Some other potentially harmful species were also found in Guanabara Bay, such as the diatoms Cerataulina pelagica, Leptocylindrus danicus, L. minimus and Dinoflagellates Akashiwo sanguinea, Oxyphysis oxytoxoides, Prorocentrum micans, P. balticum, Dinophysis acuminata, Scrippsiella cf. trochoidea (FRYXELL; VILLAC, 1999; HALLEGRAEFF; ANDERSON; CEMBELLA, 2003).

The average cell density $\left(10^{7}\right.$ cel. $\left.\mathrm{L}^{-1}\right)$, described in this study, were higher than those found in other Brazilian coastal estuaries: Sepetiba Bay-RJ $\left(10^{4}-10^{6}\right.$ cel.L-1; TENENBAUM et al. 2004), Estuary of Paraíba

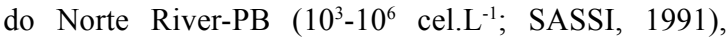
Paranaguá Bay-PR (104-10 cel.L ${ }^{-1}$; BRANDINI, 1985; BRANDINI; THAMM, 1994), São Sebastião Channel-SP (10 $10^{5}-10^{6}$ cel...-1 ; GIANESELLA et al., 1999). However, studies in Guanabara Bay carried out between 1913 and 2004 showed similar values $\left(10^{5}-10^{9}\right.$ cel.L-1 $)$ (VILLAC; TENENBAUM, 2010). These differences may be related to different environmental conditions related to changes in time and space as well as to human intervention (artificial eutrophication, dredging, navigation, etc.).

Diatoms and dinoflagellates were the predominant groups and together were responsible for more than $96 \%$ of the specific composition, in accordance with the literature that indicates their predominance in Brazilian coastal regions (BRANDINI et al., 1997). The dominance of diatoms in shallow coastal regions reflects the instability 
of this environment, where turbulence homogenizes the water column, increases nutrient concentration in the euphotic zone and reduces cell sinking (MARGALEF, 1978; SMETACEK, 1988; LLEBOT et al., 2011). The high representativeness (40\%) of chain-forming diatoms (species of Chaetoceros, Leptocylindrus, Hemiaulus, Skeletonema, Pseudo-nitzschia, Eucampia) has been related to estuarine and coastal environments (FERNANDES; BRANDINI, 2004; BÖTTJER; MORALES, 2005). According to REYNOLDS; PADISÁK and SOMMER (1993) this morphology provides a larger surface for light capture and represents an advantage over environments with high suspended solid concentrations. Laboratory assays also suggest that these organisms thrive in the environment as a result of a lower grazing pressure by microzooplankton (BODE et al., 2005).

The combination of different nutrition strategies (autotrophic and mixotrophic) may give dinoflagellates a competitive advantage over other organisms, even in the conditions of limited light that are very common in estuaries and river deltas (LALLI; PARSONS, 1993). Some taxa such as species of the genus Protoperidium and of the Order Gymnodiniales, considered heterotrophics (STEIDINGER; TANGEN, 1997), have also been frequently observed in samples. The high contribution of organisms of the Order Gymnodiniales to richness and abundance confirms VILLAC and TENENBAUM (2010) statement that Guanabara Bay dinoflagellates, although frequent and highly representative, are underestimated by virtue of the sampling and analysis procedures used in most of the studies. These dinoflagellates have extremely fragile cells that are deformed or destroyed by the commonly used fixative substances. So that a more precise identification of most taxa demands a different methodology from fixation to sample handling combined with the utilization of more advanced microscopy techniques with higher resolution.

The cyanobacteria, of the Orders Oscillatoriales and Nostocales, were also very important in phytoplankton's attaining up to $99 \%$ of abundance in some samples. These results were expected and suggest that the increase in filamentous cyanobacteria density is a response to rainy periods and high levels of eutrophication (SANTOS et al., 2007; VILLAC; TENENBAUM, 2010).

The high concentration of euglenophyceans in the study area can be associated with inland polluted waters (LIMA; TENENBAUM; VALENTIN, 2010; GUENTHER et al. 2012), whereas these organisms require organically enriched water for growth (LEE, 2008).
The presence of the diatoms Proboscia alata, Rhizosolenia setigera, Hemiaulus membranaceus, Guinardia striata, Eucampia cornuta, Dactyliosolen phuketensis and the dinoflagellates Prorocentrum balticum, Pronoctiluca pelagica, Oxytoxum gracile indicates the influence of the Tropical Water that flows along the Brazilian continental shelf mixed with Coastal Water (HASLE; SYVERSTSEN, 1997; STEIDINGER; TANGEN, 1997).

The low diversity index $\left(<2.0\right.$ bits.cell $\left.^{-1}\right)$, in $90 \%$ of samples, is a typical characteristic of systems in unstable equilibrium such as estuaries or polluted environments subject to local eutrophication (LLEBOT et al., 2011). Water mass enrichment processes first induce the proliferation of a reduced number of species and consequently a profound reduction in the species diversity index (MARGALEF, 1958; MARGALEF, 1980).

\section{CONCLUSION}

The composition and abundance of the phytoplankton of a certain region is certainly associated with the local hydrography. The interaction between water movements and phytoplankton organisms results from a combination of environmental factors. Thus the hydrodynamic properties of each region play an important role in the temporal variability and structure of phytoplankton populations (MARGALEF, 1978; ESTRADA; BERDALET, 1997). The information produced by this study will, therefore, add to knowledge of the Guanabara Bay system and will be useful for management purposes and also for the regulation of land use in the area surrounding the bay.

\section{ACKNOWLEDGEMENTS}

The authors would like to thank the Centro de Biologia Experimental Oceanus for field support and the provision of data. The authors are also grateful to their colleagues Priscila Kienteca Lange and Marcio Lincoln da Silva for their attention and kindness in translating this manuscript.

\section{REFERENCES}

AMADOR, E. S. Baía de Guanabara e ecossistemas periféricos: homem e natureza. Rio de Janeiro: Reproarte. 1997. 539 p.

BERGESCH, M.; ODEBRECHT, C.; ABREU, P. C. O. Microalgas do estuário da Lagoa dos Patos: interação entre o sedimento e a coluna de água. Oecol. Bras., v.1, p. 273-289, 1995. 
BERGESCH, M; GARCIA, M; ODEBRECHT, C. Diversity and morphology of Skeletonema species in Southern Brazil, Southwestern Atlantic Ocean. J. Phycol., v. 45, n. 6, p. 13481352, 2009.

BODE, A.; ÁLVAREZ-OSSORIO, T. GONZÁLEZ, N. LORENZO, J. RODRÍGUEZ, C. VARELA, M. VARELA, M.; M. Seasonal variability of plankton blooms in the Ria de Ferrol (NW Spain): II. Plankton abundance, composition and biomass. Estuarine, Coastal Shelf Sci., v. 63, n. 1/2, p. 285-300, 2005.

BÖTTJER, D.; MORALES, C. E. Microzooplankton grazing in a coastal embayment off Concepcion, Chile, $(\sim 36$ \{degrees\} S) during non-upwelling conditions. J. Plankton. Res., v. 27, n. 4, p. 383-391, 2005.

BRANDINI, F. P. Seasonal succession of the phytoplankton in the Bay of Paranaguá (Paraná State - Brazil). Rev. Bras. Biol., n. 45, n. 4, p. 687-694, 1985.

BRANDINI, F. P.; FERNANDES, L. F. Microalgae of the continental shelf off Paraná State, Southeastern Brazil: a review of studies. Rev. Bras. Oceanogr., v. 44, n. 1, p. 69-80, 1996.

BRANDINI, F. P.; THAMM, C. A. C. Variações diárias e sazonais do fitoplâncton e parâmetros ambientais na Baía de Paranaguá. Nerítica, v. 8, n.1/2, p. 55-72, 1994.

BRANDINI, F. P.; LOPES, R. M.; GUTSEIT, K. S.; SPACH, H. L.; SASSI, R. Planctonologia na Plataforma Continental do Brasil: diagnose e revisão bibliográfica. Brasília: Publicação do Ministério do Meio Ambiente, CIRM e Fundação de Estudos do Mar, 1997. 196 p.

CIDS - Centro Internacional de Desenvolvimento Sustentável; Baía de Guanabara - Dossiê Sócio-Ambiental, Rio de Janeiro, 2000.

CLARKE, K. R.; WARWICK, R. M. Change in marine communities: an approach to statistical analysis and interpretation. Plymouth: Plymouth Marine Laboratory, 1994. $144 \mathrm{p}$.

ClOERN, J. E., FOSTER, S. Q., KLECKNER, A. E. Phytoplankton primary production in the world's estuarinecoastal ecosystems. Biogeosciences, v. 11, p. 2477-2501, 2014.

CLOERN, J. E., JASSBY, A. D. Patterns and scales of phytoplankton variability in estuarine-coastal ecosystems. Estuar. Coasts., v. 33, n. 2, p. 230-241, 2010.

DAJOZ, R. Ecologia geral. Petrópolis: Vozes, 1983. 472 p.

ESTRADA, M.; BERDALET, E. Phytoplankton in a turbulent world. Sci. Mar., v. 61, supl. 1, p. 125-140, 1997.

FENSOME, R. A.; TAYLOR, F. J. R.; NORRIS, G.; SARJEANT, W. A. S.; WHARTON, I. D.; WILLIAMS, G. L. A classification of living and fossil dinoflagellates. Hanover: Sheridan Press, 1993. 350 p.

FERNANDES, L. F.; BRANDINI, F. P. Diatom associations in the shelf waters off Paraná State, Southern Brazil: annual variations in relation to environmental factors. Braz. J. Oceanogr., v. 52, n. 1, p. 19-34, 2004.

FRYXELL, G. A.; VILLAC, M. C. Toxic diatoms. In: STOERMER, E. F.; SMOLL, J. P. (Eds.). The Diatoms, Applications for the Environmental and Earth Sciences. 2.ed. Cambridge: Cambridge University Press, 1999. p. 419-428.
GIANESELLA, S. M. F.; KUTNER, M. B. B.; SALDANHACORREAA, F. M. P.; POMPEU, M. Assessment of plankton community and environmental conditions in São Sebastião Channel prior to the construction of a produced water outfall. Rev. Bras. Oceanogr., v. 47, n. 1, p. 29-46, 1999.

GUENTHER, M.; LIMA, I.; MUGRABE, G.; TENENBAUM, D. R.; GONZALEZ-RODRIGUEZ, E.; VALENTIN, J. L. Small time scale plankton structure variations at the entrance of a tropical eutrophic bay (Guanabara Bay, Brazil) Braz. J. Oceanogr., v. 60, n. 4, p. 405-414, 2012.

HALLEGRAEFF, G. M.; ANDERSON, D. M.; CEMBELLA, A. D. Manual on harmful marine microalgae. Monographs on Oceanographic Methodology, 11. Paris: United Nations Educational, Scientific and Cultural Organization (UNESCO) Publishing, 2003. 793 p.

HARRIS, G. P. Phytoplankton ecology: structure, function and fluctuation. London: Chapman \& Hall, 1986. 384 p.

HASLE, G. R. Using the inverted microscope. In: SOURNIA, A. (Ed.). Phytoplankton Manual. Paris: UNESCO, 1978. p. 191-196.

HASLE G. A.; SYVERTSEN E. E. Marine diatoms. In: TOMAS, C. R. (Ed.). Identifying Marine Phytoplankton. New York: Academic Press, 1997. p. 5-386.

JI, R.; DAVIS, C.; CHEN, C.; TOWNSEND, D.; MOUNTAIN, D.; BEARDSLEY, R. Influence of ocean freshening on shelf phytoplankton dynamics. Geophys. Res. Lett., 2007.

JICA. The study of the Guanabara Bay Ecosystem. Japan International Cooperation Agency. Tokyo: Kokusai Kogyo Co., Ltd, 1994.

KJERFVE, B.; RIBEIRO, C. H. A.; DIAS, G. T. M.; FILIPPO, A. M.; QUARESMA, V. S. Oceanographic characteristics of an impacted coastal bay: Baía de Guanabara, Rio de Janeiro, Brazil. Cont. Shelf Res., v. 17, n. 3, p. 1609-1643, 1997.

KJERFVE, B.; SEELIGER, U.; LACERDA, L. D. A. Summary of natural and human-induced variables on coastal marine ecosystems of Latin America. In: SEELIGER, U.; KJERFVE, B. (Org.). Coastal Marine Ecosystems of Latin America. Heidelberg, Berlin: Springer Verlag, 2001. p.341-353.

KOOISTRA, W. H. C. F., SARNO, D., BALZANO, S., GU, H., ANDERSEN, R. A.; ZINGONE, A. Global diversity and biogeography of Skeletonema species (Bacillariophyta). Protist, v. 159, n. 2, p.177-193, 2008.

KOMÁREK, J.; ANAGNOSTIDIS, K. Modern approach to the classification system of cyanophytes (Nostocales). Arch. Hydrobiol. Suppl., v. 82, n. 3, p. 247-345, 1989.

KOMÁREK, J. ANAGNOSTIDIS, K. SüBwasserflora von Mitteleuropa. Cyanoprokaryota 2. Teil: Oscillatoriales. In: BÜDEL, B.; KIENITZ, L.; GÄRTNER, G.; SCHAGERL, M. (Eds.). Sübwasserflora von Mitteleuropa 19.: München: Elsevier Spektrum Akademischer Verlag, 2005. 759 p.

LALLI, C. M.; PARSONS, T. R. Biological Oceanography: an introduction. New York: Elsevier ButterworthHeinemann, 1993. 301 p.

LEE, R. E. Phycology. 4.ed. Cambridge: Cambridge University Press, 2008. p. 245.

LEGENDRE, L.; LEGENDRE, P. Numerical Ecology. Developments in environmental Modelling, 20. New York: Elsevier, 1998. 853 p. 
LIMA, I. V.; TENENBAUM, D. R.; VALENTIN, J. L. Variação em Micro-escala temporal do Nano e Microplâncton da baía de Guanabara (RJ). In: XIII Congresso Brasileiro de Ficologia, 2010, Paraty, RJ. Anais do XIII Congresso Brasileiro de Ficologia, 2010.

LLEBOT, C.; SOLÉ, J.; DELGADO, M.; FERNÁNDEZTEJEDOR, M.; JORDI CAMP, J.; ESTRADA, M. Hydrographical forcing and phytoplankton variability in two semi-enclosed estuarine bays. J. Mar. Syst., v. 86, n. 3/4, p. 69-86, 2011.

LOBO, E. A.; CALLEGARO, V. L. M.; BENDER, E. P. Utilização de Algas Diatomáceas Epilíticas como Indicadoras da Qualidade da Água em Rios e Arroios da Região Hidrográfica do Guaíba, RS, Brasil. Santa Cruz do Sul: EDUNISC, 2002. $127 \mathrm{p}$.

MARGALEF, R. La diversidad. In: MARGALEF, R. (Org.). Ecologia. Barcelona: Omega, 1980. p. 359-382.

MARGALEF, R. Life-forms of phytoplankton as survival alternatives in an unstable environment. Oceanol. Acta, v.1, n. 4, p. 493-509. 1978.

MARGALEF, R. Succession in marine populations. In: VIRA, R. (Ed.) Advancing Frontiers of plant Sciences 2. New Delhi: Institute for Advanced Science Culture, 1963. p. 137-88.

MARGALEF, R. Temporal succession and spatial heterogeneity in phytoplankton. In: BUZZATI-TRAVERSO, A. (Ed.) Perspectives in Marine Biology. Berkeley: University of California Press, 1958. p. 323-349.

MAYR, L. M., TENENBAUM, D. R.; VILlAC, M. C. Hydrobiological characterization of Guanabara bay. In: MAGOON, O.; NEVES, C. (Eds.). Coastlines of Brazil. New York: American Society of Civil Engineers, 1989. p. 124-138.

PARSON, M. L.; DORTCH, Q. Sedimentological evidence of an increase in Pseudo-nitzschia (Bacillariophyceae) abundance in response to coastal eutrophication. Limnol. Oceanogr., v. 47, n. 2, p. 551-558, 2002.

REYNOLDS, C.S.; PADISÁK, J.; SOMMER, U. Intermediate disturbance in the ecology of phytoplankton and the maintenance of species diversity: a synthesis. Hydrobiologia, v. 249, p. 183-188, 1993.

RICARD, M. Atlas du Phytoplancton Marin. Diatomophycées. Paris: Editions Du Centre National de la Recherce Scientifique, 1987. $297 \mathrm{p}$.

ROUND, F. E.; CRAWFORD, R. M.; MANN, D. G. The diatoms: biology and morphology of the genera. Cambridge: Cambridge University Press, 1990. 747 p.

SANTOS, C. L.; SILVA, M. A. M.; SALVADOR, M. V. S. Dinâmica sazonal e os efeitos das ressacas nas praias de Niterói/RJ. Rev. Bras. Geoci., v. 34, n. 3, p. 355-360, 2004.

SANTOS, V. S.; VILLAC, M. C.; TENENBAUM, D. R.; PARANHOS, R. Auto-and heterotrophic nanoplankton and filamentous bacteria of Guanabara bay (RJ, Brazil): estimates of cell/filament numbers versus carbon content. Braz. J. Oceanogr., v. 55, p. 133-143, 2007.

SARNO, D.; KOOISTRA, W. C. H. F.; BALZANO, S.; HARGRAVES, P. E.; ZINGONE, A. Diversity in the genus Skeletonema (Bacillariophyceae): III. Phylogenetic position and morphological variability of Skeletonema costatum and Skeletonema grevillei, with the description of Skeletonema ardens sp. nov. J. Phycol., v. 43, p.156-170, 2007.
SASSI, R. Phytoplankton and environmental factors in the Paraíba do Norte river estuary, northeastern Brazil: composition, distribution and quantitative remarks. Bol. Inst. Oceanogr., v. 39, n. 2, p. 93-115, 1991.

SCHWAMBORN, R; BONECKER, S. L. C; GALVÃO, I. B.; SILVA, T. A.; NEUMANN-LEITÃO, S. Mesozooplankton grazing under conditions of extreme eutrophication in Guanabara Bay, Brazil. J. Plankton Res.,v. 26, n. 9, p. 983992, 2004.

SHAW, A. B. Time in statigraphy. New York: McGraw-Hill Book Company, 1964.

SIEBURTH, J. M.; SMETACEK, V.; LENZ, J. Pelagic ecosystem structure: heterotrophic compartments of plankton and their relationship to plankton size fractions. Limnol. Oceanogr., v. 23, n. 6, p. 1256-1263, 1978.

SILVA, M. A. M.; RESENDE, M. C. C. M.; SANTOS, C. L. Um estudo sobre a dinâmica das praias de Niterói (Baía de Guanabara, RJ). Anais da Academia Brasileira de Ciências, v. 71, n. 4, p. 962-967, 1999.

SMETACEK, V. Plankton characteristics. In: Ecosystems of the world: continental shelves. v. 2. Amsterdam: Elsevier, 1988. p. 93-130.

SOMMER, U. Plankton Ecology: succession in plankton communities. Berlin: Springer Verlag, 1989. 369 p.

SOURNIA, A. Phytoplankton Manual. Monogr. oceanogr. Methodol., U.N., v. 6, 1978.

STEIDINGER, K. A.; TANGEN, K. Dinoflagellates. In: TOMAS, C. R. (Ed.). Identifying Marine Phytoplankton. New York: Academic Press, 1997. p. 387-584.

TENENBAUM, D. R.; VILLAC, M. C.; GOMES, E. A. T.; CUPELO, A. C.; SANTOS, V. S. A new "sight" on microbial plankton ecology: coastal x oceanic system in Brazil. In: FARIA, B. M.; FARJALlA, V. F.; ESTEVES, F. A. (Eds.). Aquatic microbial ecology in Brazil. Series Oecologia Brasiliensis, v. IX. Rio de Janeiro: PPGE-UFRJ, 2001. p. 133-152.

TENENBAUM, D. R.; VILlaC, M. C.; VIANA, S. C.; MATOS, M.; HATHERLY, M.; LIMA, I. V.; MENEZES, M. Phytoplankton identification atlas Sepetiba Bay, Brazil. Rio de Janeiro/London: IOC, 2004b. 100 p.

THRONDSEN, J., 1997. The Planktonic Marine Flagellates. In: TOMAS, C.R. (ed.) Identifying Marine Phytoplankton. New York: Academic Press, 1997. p. 591-729.

THRONDSEN, J. Preservation and storage. In: SOURNIA, A., (Ed.). Phytoplankton manual. Monogr oceanogr. Methodol, 1978. p. 69-74.

TOMAS, C. R. Identifying Marine Phytoplankton. New York: Academic Press, 1997. 583 p.

UTERMÖHL, H. Perfeccionamento del metodo cuantitativo de fitoplancton. Comun. Assoc. Int. Limnol. Teor. Apl., v. 9, p. $1-89,1958$.

VALENTIN, J. L.; TENENBAUM, D. R.; BONECKER, A. C. T.; BONECKER, S. L. C.; NOGUEIRA, C. R.; VILLAC, M. C. O sistema planctônico da Baía de Guanabara: síntese do conhecimento. In: SILVA, S. H. G.; LAVRADO, H. P. (Eds). Ecologia dos ambientes costeiros do estado do Rio de Janeiro. Série Oecologia Brasiliensis. Rio de Janeiro: PPGE-UFRJ, 1999. p. 35-59.

VILLAC, M. C.; TENENBAUM, D. R. The phytoplankton of Guanabara Bay, Brazil. I. Historical account of its biodiversity. Biota Neotrop., v. 10, p. 271-293, 2010. 
VILLAC, M. C.; TENENBAUM, D. R. The coastal Pseudo-nitzschia from the state of Rio de Janeiro, Brazil. In International Conference on Harmful Algal Blooms. Hobart, v. 1, p. 34-37, 2001.
VILLAC, M. C.; DOUCETTE, G. J.; KACZMARSKA, I. Toxic marine diatoms. In: STOERMER, E. F.; SMOLL, J. P. (Eds.). The Diatoms, Applications for the Environmental and Earth Sciences. 2. ed. Cambridge: Cambridge University Press, 2010. p. 536-547. 